\title{
Influence of dehydration kinetics on T-O-T bridge breaking in zeolites with framework type STI: The case of stellerite
}

\author{
R. ARLetTi, E. Mazzucato, AND G. Vezzalini* \\ Dipartimento di Scienze della Terra, Largo S. Eufemia, 19, I-41100 Modena, Italy
}

\begin{abstract}
The thermally induced structural modifications of the natural zeolite stellerite $\left[\mathrm{Ca}_{8} \mathrm{Al}_{16} \mathrm{Si}_{56} \mathrm{O}_{144} \cdot 58 \mathrm{H}_{2} \mathrm{O}\right.$, $a=13.5947(4), b=18.1823(6)$, and $c=17.8335(6) \AA, V=4408.1(3) \AA^{3}$, space group Fmmm, framework type STI] were studied in a temperature-resolved X-ray powder diffraction experiment, using synchrotron radiation, in the temperature range RT-976 K. In the initial stage of heating (below 430 $\mathrm{K}$ ) Stellerite Phase A (space group Fmmm) is stable, and the cell volume decreases only $0.6 \%$ to this temperature. Between 430 and $490 \mathrm{~K}$ most of the water is released, the symmetry lowers, and a phase transition to the collapsed so-called Phase B (space group Amma) is observed. In this phase rotation of the $4^{2} 5^{4}$ Secondary Building Units causes cell volume contraction and deformation of the channel system. This new phase, at $530 \mathrm{~K}$, shows the statistical breaking of T-O-T bridges in the four-rings and the migration of tetrahedral atoms to new "face-sharing" tetrahedra, which partially occlude both the channels parallel to [100] and to [001]. This framework deformation is interpreted as due to the strain induced by calcium atoms on the framework to achieve better coordination after the release of water. The new structure is stable up to $750 \mathrm{~K}$ and the total volume decrease is about $8 \%$. The dehydration process causes a similar framework deformation and the transition to a collapsed phase characterized by the statistical breaking of T-O-T bridges in all zeolites with STI-type frameworks. However, comparing the results obtained with different thermal kinetics, it is possible to assume that the experimental conditions play a primary role in the mechanisms of dehydration and of framework bridge breaking.
\end{abstract}

Keywords: Zeolite, stellerite, dehydration, X-ray powder diffraction, synchrotron radiation, crystal structure

\section{INTRODUCTION}

The zeolite dehydration process has been widely studied because of the potential use of these phases as molecular sieves, sorbents, and catalysts. Knowledge of the structural modifications induced by temperature and of the stability field of these materials is of prime importance to assure their persistence and effectiveness in technological applications. The reversibility of this process, considered one of the most remarkable properties of zeolites, is not always completely fulfilled, at least in the short term. This is the case for zeolites whose frameworks are made up of differently connected chains of $4{ }^{2} 5^{4}$ Secondary Building Units (SBUs): stilbite (Slaughter 1970; Mortier 1983; Cruciani et al. 1997), barrerite (Galli and Alberti 1976; Alberti and Vezzalini 1978; Alberti et al. 1983), stellerite (Galli and Alberti 1975; Alberti et al. 1978), heulandite (Merkle and Slaughter 1968; Alberti 1972, 1973; Alberti and Vezzalini 1983; Alberti et al. 1985), clinoptilolite (Armbruster and Gunter 1991; Armbruster 1993), and brewsterite (Alberti et al. 1999, 2001; Ståhl and Hanson 1999; Sacerdoti et al. 2000), when the dehydration process results in transformation into one or more new phases. These phases are characterized by a new framework topology as a consequence of the statistical breaking of T-O-T bridges (Alberti and Vezzalini 1984).

\footnotetext{
*E-mail: giovanna@unimo.it
}

Stellerite $\left(\mathrm{Ca}_{8} \mathrm{Al}_{16} \mathrm{Si}_{56} \mathrm{O}_{144} \cdot 58 \mathrm{H}_{2} \mathrm{O}\right.$; space group Fmmm) (Galli and Alberti 1975; Miller and Taylor 1985) shares with stilbite $\left(\mathrm{Na}_{2} \mathrm{Ca}_{8} \mathrm{Al}_{18} \mathrm{Si}_{54} \mathrm{O}_{144} \cdot 60 \mathrm{H}_{2} \mathrm{O}\right.$; space group $\left.C 2 / m\right)$ (Slaughter 1970; Mortier 1983) and barrerite $\left(\mathrm{Na}_{16} \mathrm{Al}_{16} \mathrm{Si}_{56} \mathrm{O}_{144} \cdot 52 \mathrm{H}_{2} \mathrm{O}\right.$; space group Amma) (Galli and Alberti 1976) the STI framework topology (space group Fmmm) (Baerlocher et al. 2001), but the different content and distribution of extraframework cations impose different real symmetry and thermal behavior on the three phases (Alberti et al. 1978; Alberti and Vezzalini1978; Cruciani et al. 1997).

The high-temperature structures of stellerite (Alberti et al. 1978) and barrerite (Alberti and Vezzalini 1978) were studied in conventional ex situ experiments, through single-crystal diffraction, performed at room temperature, on crystals previously dehydrated in vacuum, or in air, at selected temperatures. These studies showed that, in both zeolites, the collapsed so-called B Phases (and the partially rehydrated phase $\mathrm{C}$ of barrerite, obtained cooling barrerite B to room temperature immediately after heating) have space group Amma, undergo rotation of the SBUs, with a consequent pronounced zigzag of the SBUs chains, and present statistical breaking of the same T-O-T bridge in the four-membered ring. This process is accompanied by the migration of the tetrahedral cations involved to new, partially occupied, tetrahedral sites (with three oxygen atoms in common with the previously occupied ones) in a "face-sharing" 
relationship with the original tetrahedra. Whereas in barrerite the vertices of the new tetrahedra may or may not be shared, in stellerite they are always unshared and occupied by hydroxyl groups, generating an interrupted framework characterized by a wider freedom of movement. This structural feature results in a different behavior upon rehydration; after one year in air the unit cell of stellerite reassumes the dimensions of the natural phase (phase A), while that of barrerite is similar to that of partially rehydrated phase $\mathrm{C}$.

The dehydration dynamics of stilbite were studied using in situ synchrotron X-ray powder diffraction (XRPD) (Cruciani et al. 1997). In this work the authors showed that, also in this zeolite, a contracted Phase B is formed at about $420 \mathrm{~K}$, but in this case the T-O-T bridge breaking mainly involves different tetrahedra of the four-ring compared to those observed in barrerite and stellerite.

Alberti and Vezzalini (1984) and Cruciani et al. (1997) attributed a fundamental role in this dehydration-rehydration process to the type of extraframework cations and to their coordination with framework oxygen atoms after the expulsion of most of the water.

The aims of this work are to study the dehydration dynamics of stellerite by in situ synchrotron XRPD, make a comparison with the data obtained by single-crystal ex-situ experiments, and to understand the influence of kinetics on the structural modifications induced by the dehydration process in zeolites with STI-type frameworks.

\section{EXPERIMENTAL METHODS}

The stellerite sample used in this work is from Seremida, Sardinia, Italy. Its chemical composition is $\mathrm{Na}_{1.00} \mathrm{~K}_{0.08} \mathrm{Mg}_{0.04} \mathrm{Ca}_{7.36}\left(\mathrm{Al}_{15.92} \mathrm{Si}_{56.08}\right) \mathrm{O}_{144} \cdot 56.99 \mathrm{H}_{2} \mathrm{O}$ (Alberti et al. 1978). The cell parameters determined at room temperature (RT) are: $a=$ 13.5947(4), $b=18.1823(6)$, and $c=17.8335$ (6) $\AA$.

\section{Data collection}

The temperature-resolved XRPD experiment was performed at the GILDA beam line at the European Synchrotron Radiation Facilities (Grenoble, France). The powdered sample of stellerite was carefully packed inside a $0.5 \mathrm{~mm}$ capillary open at both ends. Data was acquired in parallel Debye-Scherrer geometry, with a $\mathrm{LaB}_{6}$ refined wavelength of $0.95337 \AA$; the rotating capillary sample was heated in situ by means of hot air stream equipment, with a heating rate of $4.1 \mathrm{~K} / \mathrm{min}$ from RT up to $976 \mathrm{~K}$. The powder diffraction patterns were continuously collected, during the whole heating process, on the $4 \mathrm{~mm}$ slit-delimited slice of a translating imaging plate detector (Norby 1997; Meneghini et al. 2001) (see Fig. 1), located at a sample-to-detector distance of $204.2 \mathrm{~mm}$. A total of 75 powder patterns were extracted by integrating temperature slices of $10 \mathrm{~K}$ width and separation between subsequent integration intervals of $10 \mathrm{~K}$.

\section{Structural refinement}

The GSAS package (Larson and Von Dreele 2000) with the EXPGUI (Toby 2001) interface was used for Rietveld profile fitting and TREOR (Werner et al. 1985) for indexing and space group determination. A total of 51 patterns were fitted out of the 75 available, covering the temperature range $302-750 \mathrm{~K}$. Above this temperature the bad peak to background ratio, the broadening of the diffraction peaks, and the presence of a large amount of an amorphous phase did not allow a satisfactory structural refinement, hence only the unit-cell parameters were extracted up to $776 \mathrm{~K}$.

In the Seremida sample, impurities of calcite and quartz were detected; their amounts were refined to 2.5 and $0.5 \mathrm{wt} \%$ respectively. The lattice parameters of these phases showed a strong correlation with the zero shift values, hence, after their refinement at RT, the thermal expansion of calcite (Markgraf and Reeder 1985) and quartz (Ackermann and Sorrell 1974) was imposed on their unit cell and the $2 \theta$-zero shift for each pattern was calibrated in this way.

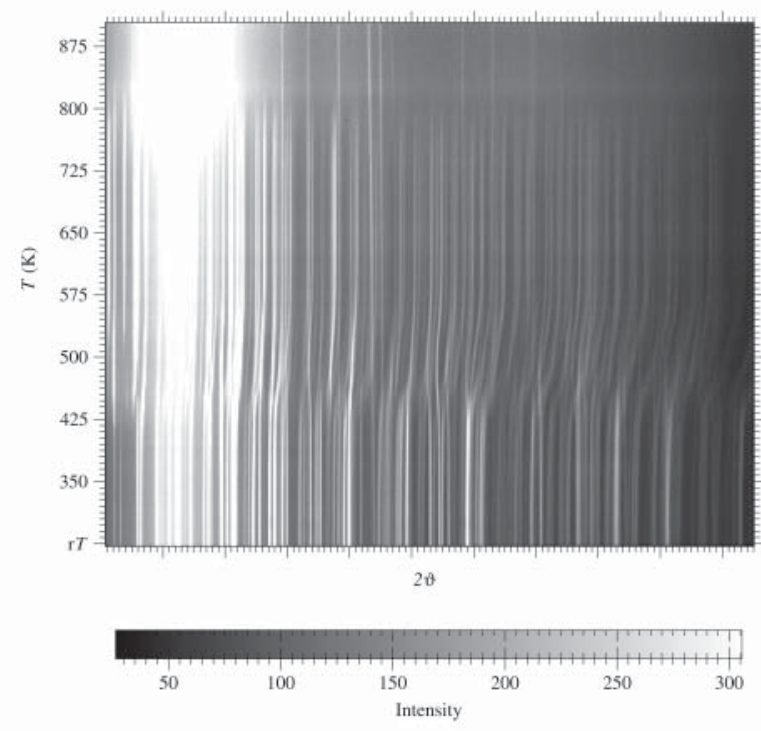

FigURE 1. Diffraction powder patterns collected during heating process on the $4 \mathrm{~mm}$ slit-delimited slice of a translating imaging plate detector.

The presence of these two phases affects the determination of thermal parameters and occupancy factors of extraframework sites of stellerite. Thus stellerite thermal parameters were refined in the initial stage of heating $(\mathrm{RT}=348 \mathrm{~K})$, when the water content was reasonably constant, and used for a linear regression calculation as a function of temperature. For water oxygen atoms this trend was assumed for all patterns, while for calcium atoms it was assumed up to $439 \mathrm{~K}$. In fact, at higher temperature the refinement of calcium thermal parameters was satisfactory owing to the decrease of electron density in the channels after water release.

The extracted Bragg peak profiles were modeled by a pseudo-Voight function with two refined coefficients (one Gaussian and one Lorentian term, Gw and Ly in GSAS terminology) and a $0.02 \%$ cut-off of the peak intensity. The background curve was fitted with a 20 refined-coefficient Chebyshev polynomial. Soft constraints were applied to the T-O distances and were gradually released after the initial stages of refinement. The thermal displacement parameters were constrained in the following way: the same value for all tetrahedral atoms, a second one for all framework oxygen atoms, a third one for extraframework cations, and a last one for water molecules.

Three scale factors, for calcite, quartz, and stellerite, respectively, the zero-shift and the unit-cell parameters of stellerite were allowed to vary for all refinement cycles. In the final cycles, the refined structural parameters for each data histogram were as follows: fractional coordinates for all atoms, occupancy factors for extraframework cations, water oxygen and partially occupied framework atoms, and thermal isotropic displacement factors, as explained above. Occupancy factors and isotropic thermal displacement factors were varied in alternate cycles. Scattering factors for neutral atoms are those listed by Cromer and Waber (1974).

At room temperature, the structure of stellerite phase A (Galli and Alberti 1975) was used as starting model for the framework atoms, whereas the extraframework sites were located by the difference-Fourier map. The Rietveld refinement of the powder patterns converged successfully up to $430 \mathrm{~K}$. Above this temperature, the difficulty in the structural refinement and the growth of new peaks suggested the possibility of a phase transition. Looking at the imaging plate, the stabilization of the patterns is evident above $490 \mathrm{~K}$ (Fig. 1); therefore the pattern at $560 \mathrm{~K}$ was utilized for pattern indexing and led to unit-cell parameters and a space group (Amma) consistent with those of stellerite phase B (Alberti et al. 1978). This structural model was assumed for patterns above $490 \mathrm{~K}$, but for the range $490-520 \mathrm{~K}$ the uninterrupted framework was assumed; the extraframework sites were located by a combination of difference-Fourier maps and least-square refinements. Above 530 $\mathrm{K}$ the refinement of tetrahedral sites occupancy factors and the presence of new maxima in the difference-Fourier map indicated the breaking of T-O-T bridges and the formation of new tetrahedra, having three oxygen atoms common to the previously occupied ones, in a "face-sharing" relationship with the original tetrahedra. At this point all histograms between 530 and $750 \mathrm{~K}$ were successfully refined using 
this last structural model. The site labeling reported by Galli and Alberti (1975) and by Alberti et al. (1978) was used for phases A and B, respectively.

Due to the difficulty in the structural refinement, only the unit cell parameters were derived in the temperature range $430-484 \mathrm{~K}$.

The structures refined for Phase A at $430 \mathrm{~K}$ and for Phase B at $484 \mathrm{~K}$ were used in a two-phase refinement in the temperature range $448-457 \mathrm{~K}$ to determine the unit-cell parameters of both phases.

The refinement details for patterns at 302,503, and $740 \mathrm{~K}$ are reported in Table 1 ; the refined atomic coordinates, occupancy factors, and thermal parameters for the structures at the same temperatures are reported in Table 2; the bond distances are reported in Table 3 and observed, calculated, and difference powder diffraction patterns are shown in Figure 2.

\section{RESULTS}

The framework of stellerite (Fig. 3a) can be described by the joining of the $4{ }^{2} 5^{4}$ SBUs to form chains parallel to $\mathbf{c}$. Such chains are laterally connected by $6 \mathrm{O}$ atom bridges to form layers parallel to (010). Another two oxygen bridges link the layers to each other to form a three-dimensional net. This results in two systems of channels: a ten-ring channel running parallel to $\mathbf{a}$ and an eight-ring channel running along $\mathbf{c}$. One extraframework site, occupied by calcium atoms, and seven sites, partially occupied by water molecules, were localized by Galli and Alberti (1975) in the stellerite structure. The so-called phase A, stable at room $T$, has symmetry Fmmm, which is also the topological symmetry of STI structure-type zeolites, owing to the symmetrical distribution of only $\mathrm{Ca}$ atoms on the mirror plane perpendicular to $\mathbf{a}$.

In the initial stage of heating (below $430 \mathrm{~K}$ ) stellerite phase $\mathrm{A}$ is stable, the $b$ and $c$ parameters decrease by 0.4 and $0.3 \%$, respectively, while $a$ slightly increases, with a consequent decrease of the cell volume of $0.6 \%$ (Fig. 4). Between 430 and $503 \mathrm{~K}$, a phase transition to the so-called Phase B (Alberti et al. 1978) occurs, the symmetry lowers to Amma and the volume further contracts by about $4.4 \%$, notwithstanding the increase in $a$. In this $T$ range, owing to the coexistence of both A and $\mathrm{B}$ phases, only the unit-cell parameters were derived: phase A up to $439 \mathrm{~K}$, phase $\mathrm{B}$ from $466 \mathrm{~K}$ on, and both phases at 448 and 457 K (Fig. 4).

Above the transition the volume contraction continues up to about $600 \mathrm{~K}$, with a total volume variation of $7.6 \%$, while maintaining the same space group. At $776 \mathrm{~K}$ the cell parameters of stellerite are $a=13.543(1), b=17.532(2)$, and $c=17.096(2)$ $\AA$, with a total volume decrease of $7.8 \%$. Above this temperature the material undergoes complete amorphization.

TABLE 1. Experimental and refinement parameters for stellerite at 302,503 , and $740 \mathrm{~K}$

\begin{tabular}{lccc}
\hline Temperature & $302 \mathrm{~K}$ & $503 \mathrm{~K}$ & $740 \mathrm{~K}$ \\
\hline Space group & Fmmm & Amma & $A m m a$ \\
$a(\AA)$ & $13.5947(4)$ & $13.6629(6)$ & $13.5426(8)$ \\
$b(\AA)$ & $18.1823(6)$ & $17.6064(9)$ & $17.557(1)$ \\
$C(\AA)$ & $17.8335(6)$ & $17.3629(9)$ & $17.102(1)$ \\
Cell volume $\left(\AA^{3}\right)$ & $4408.1(3)$ & $4176.7(5)$ & $4066.2(7)$ \\
$R_{\mathrm{p}}(\%)$ & 4.74 & 5.17 & 4.24 \\
$R_{\text {wp }}(\%)$ & 6.43 & 7.02 & 5.97 \\
$R_{F * * 2}(\%)$ & 9.57 & 8.07 & 12.69 \\
$X^{2}$ & 21.90 & 25.79 & 19.65 \\
No. of variables & 76 & 91 & 78 \\
No. of observations & 2512 & 2535 & 2559 \\
No. of reflections & 938 & 1690 & 1682 \\
\hline
\end{tabular}

Framework

The framework of stellerite Phase B is characterized, as previously shown in the single crystal study by Alberti et al. (1978), by the rotation of the secondary building units around

TABLE 2. Fractional coordinates, thermal parameters, and occupancy factors at 302,503 , and $740 \mathrm{~K}$

\begin{tabular}{|c|c|c|c|c|c|}
\hline Atom & $x / a$ & $y / b$ & $z / c$ & Occ. & $U_{\text {iso }}$ \\
\hline \multicolumn{6}{|c|}{$302 \mathrm{~K}$} \\
\hline $\mathrm{T} 1$ & $0.3847(3)$ & $0.3068(3)$ & $0.3787(2)$ & 1.0 & $0.0337(9)$ \\
\hline T3 & $0.3034(5)$ & $0.4114(3)$ & 0.5 & 1.0 & $0.0337(9)$ \\
\hline T4 & $0.3859(4)$ & $0.1832(4)$ & 0.5 & 1.0 & $0.0337(9)$ \\
\hline T5 & 0.25 & 0.25 & 0.25 & 1.0 & $0.0337(9)$ \\
\hline 01 & $0.3151(5)$ & $0.3094(5)$ & $0.2995(4)$ & 1.0 & $0.043(1)$ \\
\hline $\mathrm{O} 3$ & $0.3716(5)$ & $0.2353(5)$ & $0.4265(4)$ & 1.0 & $0.043(1)$ \\
\hline $\mathrm{O} 4$ & $0.3548(7)$ & $0.3804(5)$ & $0.4205(5)$ & 1.0 & $0.043(1)$ \\
\hline O7 & 0.5 & $0.3164(7)$ & $0.3532(6)$ & 1.0 & $0.043(1)$ \\
\hline 08 & $0.3179(9)$ & $0.1121(6)$ & 0.5 & 1.0 & $0.043(1)$ \\
\hline O9 & $0.311(1)$ & 0.5 & 0.5 & 1.0 & $0.043(1)$ \\
\hline 010 & 0.5 & $0.148(1)$ & 0.5 & 1.0 & $0.043(1)$ \\
\hline $\mathrm{Ca}$ & 0.5 & 0.0 & $0.2920(4)$ & $0.89(1)$ & $0.042(2)$ \\
\hline W1 & $0.401(4)$ & $0.117(3)$ & $0.307(3)$ & $0.27(2)$ & $0.091(6)$ \\
\hline W2 & 0.5 & $0.131(1)$ & $0.302(1)$ & $0.84(2)$ & $0.091(6)$ \\
\hline W3 & $0.460(3)$ & 0.0 & $0.419(1)$ & $0.46(1)$ & $0.091(6)$ \\
\hline W4 & $0.349(3)$ & $0.071(2)$ & $0.330(2)$ & $0.30(2)$ & $0.091(6)$ \\
\hline W5 & $0.420(1)$ & 0.5 & $0.336(1)$ & $0.64(2)$ & $0.091(6)$ \\
\hline W7 & $0.315(2)$ & $0.053(2)$ & $0.246(2)$ & $0.27(1)$ & $0.091(6)$ \\
\hline \multicolumn{6}{|c|}{$503 \mathrm{~K}$} \\
\hline $\mathrm{T} 1$ & $0.1373(7)$ & $0.3340(5)$ & $0.1346(6)$ & 1.0 & $0.037(1)$ \\
\hline $\mathrm{T} 1 \mathrm{P}$ & $0.1369(6)$ & $0.2851(5)$ & $0.3792(5)$ & 1.0 & $0.037(1)$ \\
\hline T3 & $0.0505(7)$ & $0.4087(4)$ & $0.2819(5)$ & 1.0 & $0.037(1)$ \\
\hline $\mathrm{T} 4$ & $0.1350(7)$ & $0.1882(5)$ & $0.2330(5)$ & 1.0 & $0.037(1)$ \\
\hline T5 & 0 & $0.2969(7)$ & 0 & 1.0 & $0.037(1)$ \\
\hline 01 & $0.066(1)$ & $0.3577(7)$ & $0.0588(9)$ & 1.0 & $0.053(3)$ \\
\hline O1P & $0.064(1)$ & $0.2658(7)$ & $0.4557(8)$ & 1.0 & $0.053(3)$ \\
\hline $\mathrm{O} 3$ & $0.127(1)$ & $0.2447(7)$ & $0.1580(9)$ & 1.0 & $0.053(3)$ \\
\hline O3P & $0.117(1)$ & $0.2164(9)$ & $0.3188(8)$ & 1.0 & $0.053(3)$ \\
\hline $\mathrm{O} 4$ & $0.100(1)$ & $0.3927(9)$ & $0.1956(8)$ & 1.0 & $0.053(3)$ \\
\hline O4P & $0.117(1)$ & $0.3672(8)$ & $0.3470(9)$ & 1.0 & $0.053(3)$ \\
\hline O7 & 0.25 & $0.363(1)$ & $0.103(1)$ & 1.0 & $0.053(3)$ \\
\hline O7P & 0.25 & $0.287(1)$ & $0.410(1)$ & 1.0 & $0.053(3)$ \\
\hline 08 & $0.0738(9)$ & $0.1158(8)$ & $0.212(1)$ & 1.0 & $0.053(3)$ \\
\hline 09 & $0.047(1)$ & 0.5 & $0.289(1)$ & 1.0 & $0.053(3)$ \\
\hline 010 & 0.25 & $0.162(1)$ & $0.231(1)$ & 1.0 & $0.053(3)$ \\
\hline Ca1 & 0.25 & $0.179(4)$ & $0.067(4)$ & $0.15(1)$ & 0.083 \\
\hline $\mathrm{Ca} 4$ & 0.25 & 0.5 & $0.171(10)$ & $0.09(2)$ & 0.083 \\
\hline $\mathrm{Ca} 5$ & $0.080(19)$ & 0.5 & $0.093(1)$ & $0.40(1)$ & 0.083 \\
\hline Ca6 & $0.083(3)$ & 0 & $-0.018(3)$ & $0.23(1)$ & 0.083 \\
\hline W1 & 0.25 & 0 & $0.343(7)$ & $0.44(4)$ & 0.132 \\
\hline W2 & 0.25 & $0.094(13)$ & $0.431(14)$ & $0.13(3)$ & 0.132 \\
\hline W3 & 0.25 & 0.5 & $0.410(3)$ & $0.83(4)$ & 0.132 \\
\hline W4 & 0.25 & 0 & $0.213(6)$ & $0.44(5)$ & 0.132 \\
\hline \multicolumn{6}{|c|}{$740 \mathrm{~K}$} \\
\hline T1 & $0.138(1)$ & $0.334(1)$ & $0.137(1)$ & $0.62(1)$ & $0.063(2)$ \\
\hline $\mathrm{T} 1 \mathrm{P}$ & $0.1348(8)$ & $0.2745(7)$ & $0.3762(6)$ & 1.0 & $0.063(2)$ \\
\hline T3 & $0.0551(9)$ & $0.4134(6)$ & $0.2873(8)$ & 1.0 & $0.063(2)$ \\
\hline $\mathrm{T} 4$ & $0.1337(8)$ & $0.1751(8)$ & $0.2243(7)$ & 1.0 & $0.063(2)$ \\
\hline T5 & 0 & $0.3091(9)$ & 0 & 1.0 & $0.063(2)$ \\
\hline T1D & $0.141(1)$ & $0.4109(7)$ & $0.116(1)$ & $0.38(1)$ & $0.063(2)$ \\
\hline 01 & $0.073(1)$ & $0.363(1)$ & $0.058(1)$ & 1.0 & $0.084(3)$ \\
\hline O1P & $0.072(1)$ & $0.2482(8)$ & $0.455(1)$ & 1.0 & $0.084(3)$ \\
\hline $\mathrm{O} 3$ & $0.128(1)$ & $0.239(1)$ & $0.152(1)$ & 1.0 & $0.084(3)$ \\
\hline O3P & $0.123(1)$ & $0.210(1)$ & $0.3107(9)$ & 1.0 & $0.084(3)$ \\
\hline $\mathrm{O} 4$ & $0.118(1)$ & $0.396(1)$ & $0.206(1)$ & 1.0 & $0.084(3)$ \\
\hline O4P & $0.110(1)$ & $0.3577(9)$ & $0.345(1)$ & 1.0 & $0.084(3)$ \\
\hline 07 & 0.25 & $0.367(2)$ & $0.100(2)$ & 1.0 & $0.084(3)$ \\
\hline O7P & 0.25 & $0.272(2)$ & $0.406(2)$ & 1.0 & $0.084(3)$ \\
\hline 08 & $0.071(1)$ & $0.100(1)$ & $0.214(1)$ & 1.0 & $0.084(3)$ \\
\hline 09 & $0.082(2)$ & 0.5 & $0.310(2)$ & 1.0 & $0.084(3)$ \\
\hline 010 & 0.25 & $0.142(1)$ & $0.221(2)$ & 1.0 & $0.084(3)$ \\
\hline OD & $0.139(3)$ & 0.5 & $0.097(2)$ & $0.76(3)$ & $0.084(3)$ \\
\hline Ca1 & 0.25 & $0.243(1)$ & $0.051(1)$ & $0.45(1)$ & $0.044(7)$ \\
\hline $\mathrm{Ca} 4$ & 0.25 & 0.5 & $0.187(2)$ & $0.38(2)$ & $0.044(7)$ \\
\hline W1 & 0.25 & 0 & $0.303(4)$ & $0.61(4)$ & 0.180 \\
\hline
\end{tabular}



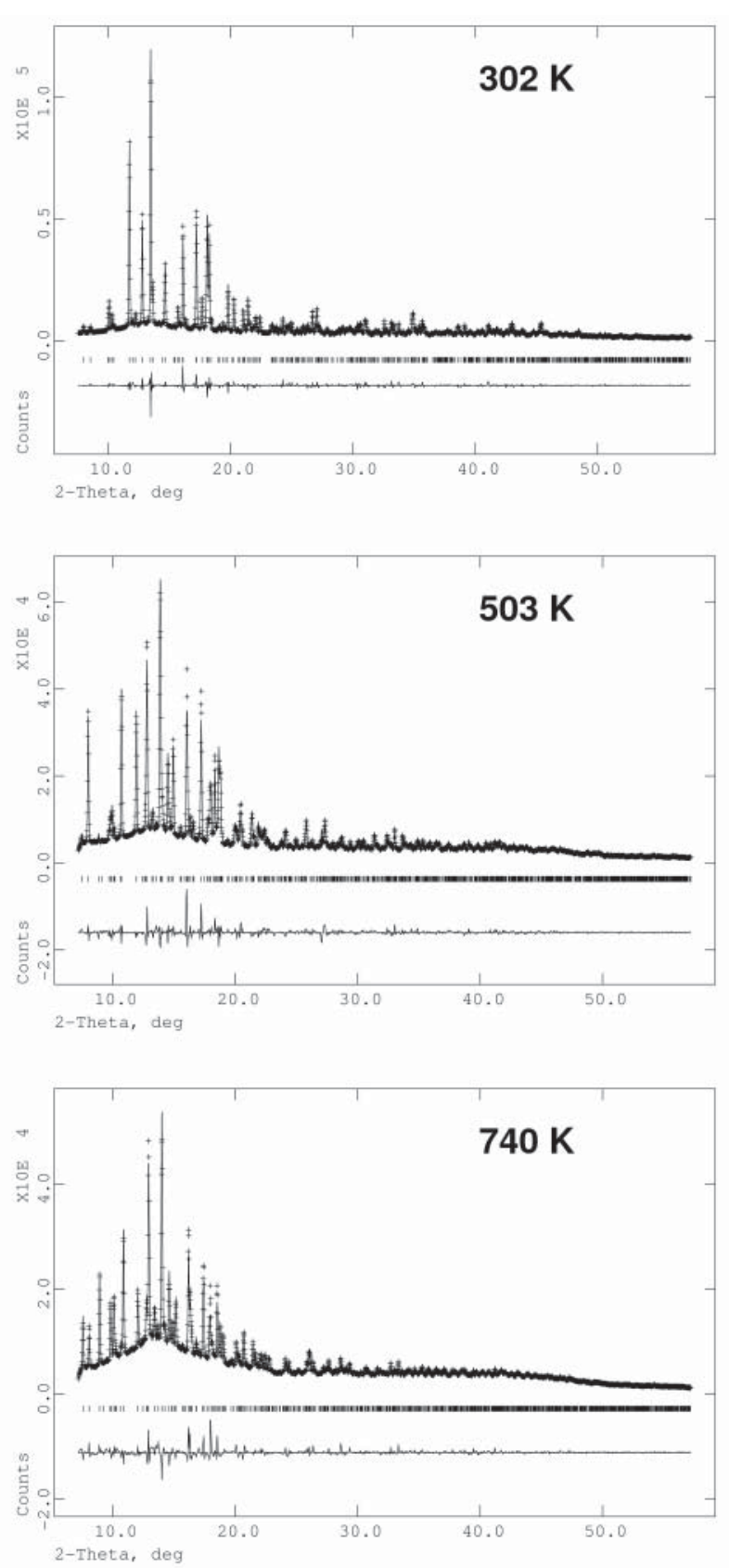

FigURE 2. Observed (dotted line) and calculated (continuous line) diffraction patterns and final difference curve from Rietveld refinements of stellerite at RT (a), $503 \mathrm{~K}(\mathbf{b})$, and $740 \mathrm{~K}(\mathbf{c})$.

their gravity center, which causes a zigzag shape of the chains parallel to c, a cell-volume contraction, and a deformation of the channels parallel to the $\mathbf{a}$ and $\mathbf{c}$ axes (Fig. 3b). This rotation is highlighted in Figure 5, where the T5-T5-T5 angle is plotted vs. temperature. Along with this framework deformation, above $530 \mathrm{~K}$ we observe the statistical breaking of the oxygen bridge T1-O3-T4 in the four-ring and the migration of one of the two involved tetrahedral cations from $\mathrm{T} 1$ to a new "face-sharing" tetrahedron called T1D (Fig. 3c and Tables 2 and 3). In contrast,
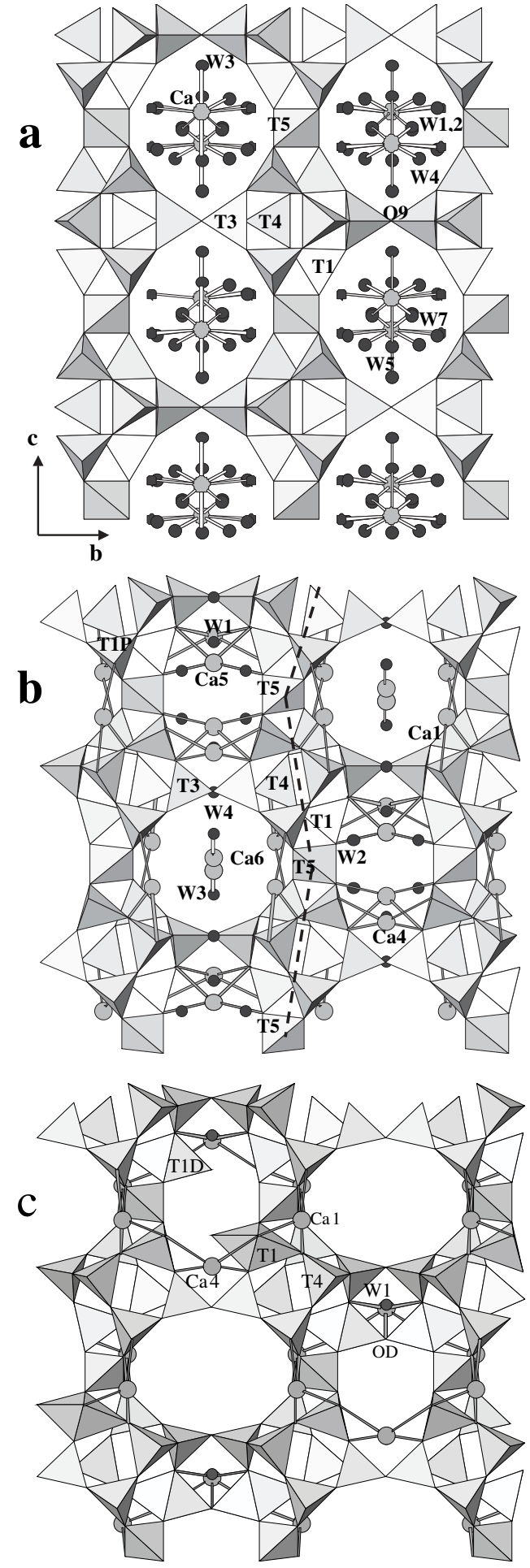

FIGURE 3. Projection along [100] of refined structure of stellerite Phase A at RT (a) and stellerite Phase B at 503 K (b) and 740 K (c). Ca atoms: large light gray spheres; $\mathrm{W}$ oxygen atoms: small dark gray spheres; $\mathrm{Ca}-\mathrm{W}$ bond distances, less than $3.0 \AA$, white bars; $\mathrm{Ca}-\mathrm{O}_{\text {framework }}$, less than $3.0 \AA$, light gray bars. In Figure (b) the T5-T5-T5 angle is shown. In Figure (c) some possible configurations of the interrupted framework are shown; obviously when T1D is present T1 is empty. 
TABLE 3. Interatomic distances in stellerite at 302,503 , and $740 \mathrm{~K}$

\begin{tabular}{|c|c|c|c|c|}
\hline & $302 \mathrm{~K}$ & & $503 \mathrm{~K}$ & $740 \mathrm{~K}$ \\
\hline T1-O1 & $1.701(6)$ & $\mathrm{T} 1-01$ & $1.692(9)$ & $1.68(1)$ \\
\hline $\mathrm{T} 1-\mathrm{O} 3$ & $1.565(9)$ & $\mathrm{T} 1-\mathrm{O} 3$ & $1.63(1)$ & $1.69(1)$ \\
\hline T1-O4 & $1.585(8)$ & $\mathrm{T} 1-\mathrm{O} 4$ & $1.56(1)$ & $1.63(1)$ \\
\hline \multirow[t]{5}{*}{ T1-O7 } & $1.642(5)$ & $\mathrm{T} 1-\mathrm{O} 7$ & $1.714(9)$ & $1.75(1)$ \\
\hline & & T1P-01P & $1.693(9)$ & $1.66(1)$ \\
\hline & & T1P-O3P & $1.622(9)$ & $1.60(1)$ \\
\hline & & T1P-O4P & $1.573(9)$ & $1.59(1)$ \\
\hline & & T1P-07P & $1.633(8)$ & $1.64(1)$ \\
\hline \multirow[t]{2}{*}{ T3-O4[×2] } & $1.678(8)$ & T3-O4 & $1.67(1)$ & $1.66(1)$ \\
\hline & & T3-O4P & $1.63(1)$ & $1.57(1)$ \\
\hline T3-08 & $1.703(11)$ & T3-08 & $1.75(1)$ & $1.72(1)$ \\
\hline T3-09 & $1.615(6)$ & T3-09 & $1.614(8)$ & $1.61(1)$ \\
\hline T4-O3 [×2] & $1.628(8)$ & $\mathrm{T} 4-\mathrm{O} 3$ & $1.642(9)$ & $1.68(1)$ \\
\hline T4-O8 & $1.588(10)$ & T4-O3P & $1.589(9)$ & $1.61(1)$ \\
\hline \multirow[t]{2}{*}{ T4-O10 } & $1.677(8)$ & T4-O8 & $1.57(1)$ & $1.60(1)$ \\
\hline & & T4-010 & $1.636(8)$ & $1.68(1)$ \\
\hline \multirow[t]{6}{*}{ T5-O1 [×4] } & $1.653(7)$ & T5-O1 [×2] & $1.731(7)$ & $1.699(8)$ \\
\hline & & $\mathrm{T} 5-01 \mathrm{P}[\times 2]$ & $1.606(7)$ & $1.595(8)$ \\
\hline & & T1D-O1 & & $1.58(1)$ \\
\hline & & T1D-O4 & & $1.60(1)$ \\
\hline & & T1D-O7 & & $1.69(1)$ \\
\hline & & T1D-OD & & $1.60(1)$ \\
\hline Ca-W1 [×4] & $2.54(5)$ & Ca1-O1P [×2] & & $2.92(2)$ \\
\hline Ca-W2 [×2] & $2.39(2)$ & $\mathrm{Ca} 1-\mathrm{O} 3[\times 2]$ & $2.58(5)$ & $2.39(2)$ \\
\hline Ca-W3 [x2] & $2.34(2)$ & $\mathrm{Ca} 1-\mathrm{O} 7$ & & $2.35(4)$ \\
\hline Ca-W4 [×4] & $2.51(3)$ & Ca1-O7P & $2.80(7)$ & $2.48(3)$ \\
\hline Ca-W5 [×2] & $2.54(2)$ & Ca1-010 & $2.86(7)$ & \\
\hline Ca-W7 [×4] & $2.82(3)$ & & & \\
\hline W1-01 & $2.58(5)$ & Ca4- OD [×2] & & $2.15(4)$ \\
\hline \multirow[t]{2}{*}{ W1-O3 } & $3.06(4)$ & Ca4- O4 $[\times 4]$ & $2.81(3)$ & $2.58(2)$ \\
\hline & & Ca4- O7 [×2] & $2.69(8)$ & $2.77(4)$ \\
\hline \multirow[t]{2}{*}{ W2-O7 } & $2.94(2)$ & & & \\
\hline & & $\mathrm{Ca} 5-\mathrm{O} 1[\times 2]$ & $2.58(1)$ & \\
\hline W3-08 [×2] & $3.16(2)$ & $\mathrm{Ca} 5-\mathrm{O} 4[\times 2]$ & $2.61(2)$ & \\
\hline \multirow[t]{2}{*}{ W3-O10 [×2] } & $3.10(2)$ & & & \\
\hline & & Ca6-W3 & $2.60(4)$ & \\
\hline W4-O1 & $3.16(3)$ & & & \\
\hline \multirow[t]{2}{*}{ W4-08 } & $3.14(4)$ & & & \\
\hline & & W1-O10 [×2] & $2.85(4)$ & \\
\hline \multirow[t]{2}{*}{ W5-O4 [×2] } & $2.79(1)$ & & & \\
\hline & & W2-O7 & $3.08(24)$ & \\
\hline \multirow{4}{*}{ W7-O1 } & $2.62(3)$ & & & \\
\hline & & W3-O4P [×4] & $3.15(2)$ & \\
\hline & & W4-08 $[\times 4]$ & $3.15(1)$ & \\
\hline & & W4-O10 [×2] & $2.88(2)$ & \\
\hline
\end{tabular}

an analogous migration of T4 to a new tetrahedral site was not observed. The new tetrahedron T1D shares three oxygen atoms with the previously occupied one, whereas the new vertex (OD) is located on the mirror plane perpendicular to $b$. The percentage of broken bridges increases with temperature as shown in Figure 6 , where the occupancies of $\mathrm{OD}, \mathrm{T} 1$, and T1D are reported. If two T1D tetrahedra, equivalent by a mirror plane perpendicular to $\mathbf{b}$, were always linked, the occupancy factors of OD and T1D would have the same value and an oxygen atom would always occupy the OD site. Instead, if the OD site occupancy was double the one refined for T1D, the tetrahedra would always be unconnected and a hydroxyl group would occupy the OD site. Since, in this study, the occupancy of the OD site is almost double that of T1D we can assume that the new tetrahedra are mainly unconnected. However, as explained in the following section regarding the extraframework cations, the percentage of oxygen atoms in this site could be overestimated. In any case, both channel systems are partially occluded at high temperature, even if by the presence of only one T1D tetrahedron.
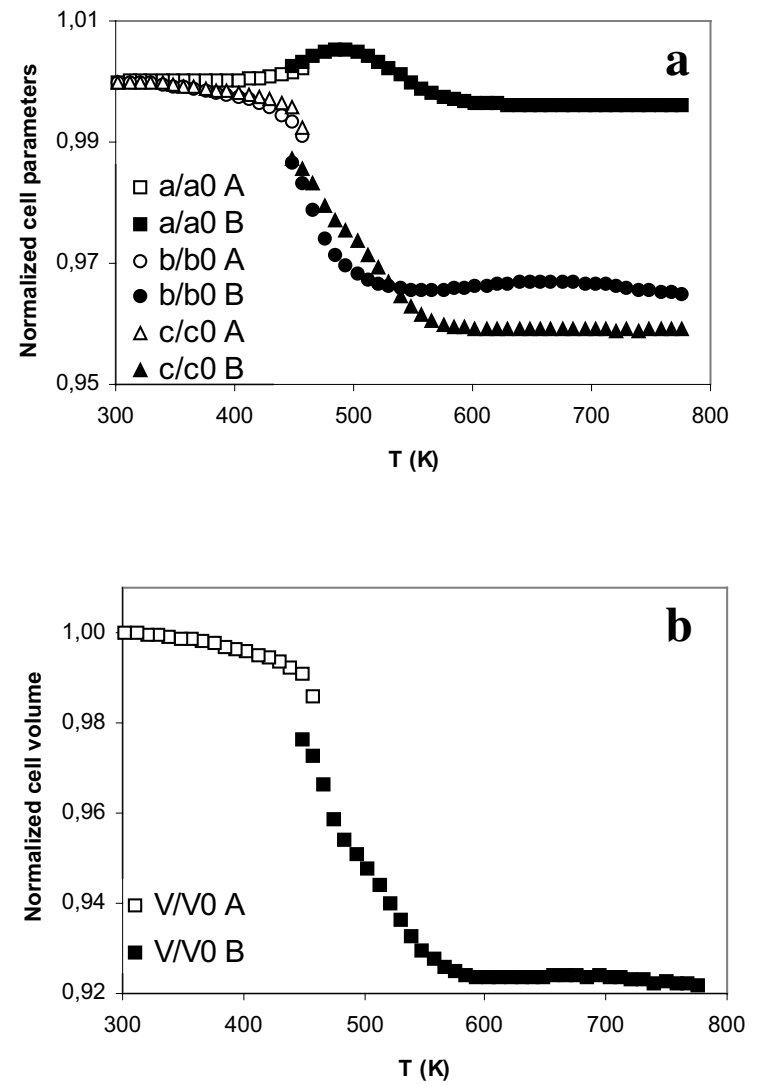

FIGURE 4. Plot of normalized unit-cell parameters (a) and unit cell volume (b) of stellerite vs. temperature. A and B labels refer to phase $\mathrm{A}$ and $\mathrm{B}$, respectively.

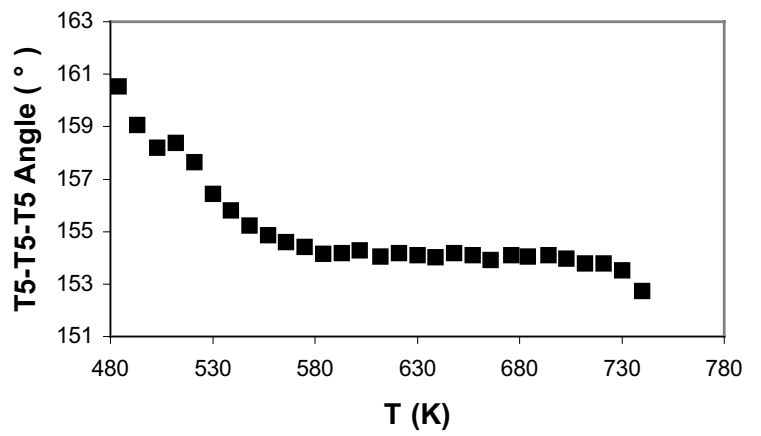

FigURE 5. T5-T5-T5 angle, as calculated from the structural refinements above phase transition, vs. temperature.

\section{Extraframework sites}

At room temperature the structure refinement located six sites occupied by water molecules (58 water molecules in the unit cell), almost corresponding to those found by Galli and Alberti (1975), with the exception of W4, which was located out of the mirror plane perpendicular to $\mathbf{b}$, and W6, which was not located. The structure refinements of the patterns below $366 \mathrm{~K}$ showed that the water content of stellerite is maintained. A slight decrease in the water content is observed up to $412 \mathrm{~K}$, 


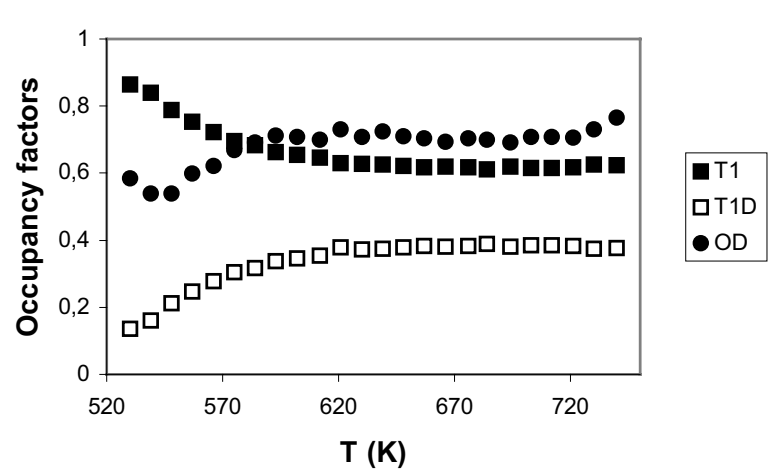

FIGURE 6. Refined occupancies of "face-sharing" tetrahedral sites and of OD site vs. temperature above $530 \mathrm{~K}$.

while most water is released in the range $430-500 \mathrm{~K}$ (Fig. 7). At $503 \mathrm{~K}$, in fact, only 11 water molecules were localized at four partially occupied sites, near but not exactly matching those of RT; of these, W1 corresponds to the unique water molecule site found in single crystal experiment on phase $\mathrm{B}, \mathrm{W} 3$ coordinates a calcium atom in $\mathrm{Ca} 6$, whereas the other molecules are bonded only to framework oxygen atoms (see Tables 2 and 3 and Fig. $3 \mathrm{~b})$. Up to $550 \mathrm{~K}$ a further six water molecules are gradually lost and the remaining five molecules are distributed over two sites (Fig. 7). Above this temperature the water content steadily decreases and at $650 \mathrm{~K}$ stabilizes at 2.5 molecules at only one W1 water site. In Figure 3 the position of water molecules is shown for stellerite at RT, 503, and $740 \mathrm{~K}$.

At RT a unique, partially occupied site $(\mathrm{Ca})$ was localized at the intersection of the two channel systems (Fig. 3a and Table 2). Above the transition to the Amma phase, at about $500 \mathrm{~K}$, a distribution of calcium atoms over four partially occupied sites was observed. Three of the new sites are on the mirror planes perpendicular $\mathbf{b}$, two in the channel at $b=1 / 2(\mathrm{Ca} 4, \mathrm{Ca} 5)$ and one (Ca6) in the channel at $b=0$ (Fig. 3b and Table 2). Ca1 and Ca4 correspond to the cation sites of the single-crystal study of Alberti et al. (1978). With the exception of Ca6, all the cation sites are coordinated only to framework oxygen atoms (Table 3 ).

The $\mathrm{Ca} 4$ and $\mathrm{Ca} 1$ cation sites remain in the same position up to the highest temperature, but their occupancy factors strongly increase. The $\mathrm{Ca} 6$ site, which at $503 \mathrm{~K}$ was assumed to be occupied by calcium, at higher temperature was attributed to water molecules on the basis of its occupancy factor and bond distances. As shown in Figures $3 \mathrm{~b}$ and $\mathrm{c}$ the position of $\mathrm{Ca} 5$ almost corresponds to that of the new oxygen site OD. Attempts to refine this position as occupied by water failed because of the excessively short distances to the framework oxygen atoms and excessively high occupancy factor. In fact, during the T1O3-T4 bridge breaking $(530 \mathrm{~K})$ the calcium atoms migrate to a new position $\mathrm{Ca}^{5}$ ' - with $0,0,1 / 2$ fractional coordinates - while the $\mathrm{Ca} 5$ site can be alternatively occupied by both calcium and oxygen atoms. Gradually this site fills with oxygen atoms, reaching maximum occupancy (76\%) at $740 \mathrm{~K}$ (Table 2 and Fig. 6). Consequently, the percentage of oxygen atoms present in OD could be overestimated due to residual calcium atoms.

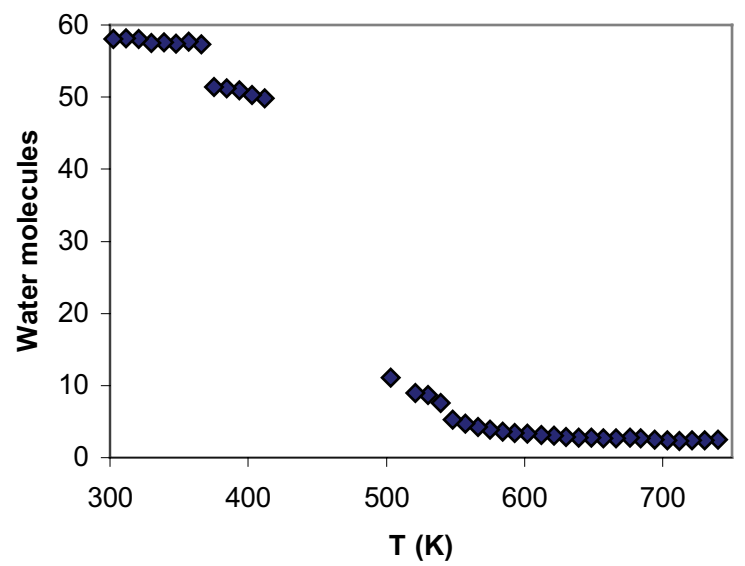

FigURE 7. Total water content, as calculated from the refined occupancies of W sites, vs. temperature.

\section{DISCUSSION OF RESULTS}

The variation of unit-cell parameters observed in stellerite is related both to thermally induced framework deformation and to the evolution of the extraframework species. In particular the contraction of $b$ and $c$ is due to the zigzag imposed on the tetrahedral chains during the dehydration process, whereas the slight lengthening of the $a$ parameter, observed during water loss, can be interpreted as a consequence of the decreased number of hydrogen bonds between the water molecules and the framework oxygen atoms. The same effect on $b$ and $c$ cell parameters was not evident owing to the greater effect of the framework deformation along these directions.

Comparing the thermal behavior of stellerite discussed in this work with the single-crystal study (Alberti et al. 1978), we can observe a smaller volume decrease in the powder experiment (8\% against $12 \%$ ). This discrepancy can be attributed to the different dehydration conditions: continuous and fast heating rate in air versus prolonged heating at constant temperature in vacuum. Hence we can assume that slower kinetics results in a more collapsed and stable structure.

The framework deformation and the subsequent T-O-T bridge-breaking, observed during the thermal dehydration of all STI type structure zeolites, have been interpreted by several authors (Alberti and Vezzalini 1978, 1984; Alberti et al. 1978; Cruciani et al. 1997) as due to the strain induced by extraframework cations on the framework oxygen atoms to achieve a better coordination after water release. In this study, after the water loss, the unique Ca site present at RT spreads into more sites, which contribute to the tetrahedral chain deformation and to the T-O-T bridge breaking. In fact, the calcium atoms present in these new sites apply a strain on the $\mathrm{T} 1$ and $\mathrm{T} 4$ tetrahedra as a result of being strongly bonded to some of their oxygen atoms (Table 3). A different behavior was observed in stellerite Phase B during ex situ single crystal experiments, where the structure refinement was carried out at room temperature on a crystal dehydrated in vacuum at $493 \mathrm{~K}$ for about 24 hours. In that study a different bridge (T1P-O3P-T4), although in the same four-ring, was broken, no new oxygen bridge can be formed and thus a large mobility of the framework and a large volume contraction is pos- 
sible. For this reason the return of the cell dimensions of phase A upon re-hydration is possible. Also the present study, where again the framework of phase B was found mainly interrupted, supports the reversibility of stellerite cell-volume variation upon rehydration. Moreover, Alberti et al. (1978) found only one water molecule in stellerite B, an amount much lower than that found in the present study at the same temperature; this effect again can be explained by the different experimental conditions.

In the in situ dehydration study of stilbite (Cruciani et al. 1997) the cell volume contraction $(7.7 \%)$ is comparable with that of stellerite reported here; however, the transition to stilbite phase B occurs at lower temperature compared to stellerite. Again, the different dehydration dynamics could be the reason for the different behavior. In fact, in the experiment performed by Cruciani et al. (1997), each histogram was accumulated for 5 min at constant temperature, thus shifting all the thermal effects to lower $T$.

It is rather surprising that in the in situ temperature-resolved studies of stilbite and stellerite the same T-O-T bond is involved in the breaking, whereas in both barrerite and stellerite, studied by ex situ experiments, a different bond of the four-ring is involved in the breaking. Moreover, during the XRPD experiments only one of the two tetrahedral atoms migrates to a new "face sharing" tetrahedron, while in the single-crystal study both tetrahedral atoms form new tetrahedra. In this latter case the system probably has enough time to reach conditions of major equilibrium. Therefore we can conclude that the experimental conditions play a primary role in the dehydration process of STI type zeolites: in particular the different kinetics induces a different evolution of the extraframework species (both water molecules and extraframework cations) with a consequent influence on the deformation and breaking of the framework. This effect has to be considered when possible applications of these zeolites are examined.

\section{ACKNOWLEDGMENTS}

The authors are indebted to G. Cruciani and A. Gualtieri for useful suggestions during the experiments and Rietveld structural refinements. The European Synchrotron Radiation Facility is kindly acknowledged for allocation of beam time under proposal CH545. This work was supported by Italian MIUR (FIRB2002 "Proprietà ed applicazioni tecnologiche di minerali e loro analoghi di sintesi”).

\section{REFERENCES CITED}

Ackermann, R.S. and Sorrell, C.A. (1974) Thermal expansion and the high-low transformation in quartz. I. High-Temperature X-ray studies. Journal of Applied Crystallography, 7, 431-437.

Alberti, A. (1972) On the crystal structure of the zeolite heulandite. Tschermaks Mineralogische Petrographische Mitteilungen, 18, 129-146.

- - - (1973) The structure type of heulandite B (heat-collapsed phase). Tschermaks Mineralogische Petrographische Mitteilungen, 19, 173-184.

Alberti, A. and Vezzalini, G. (1978) Crystal structures of heat-collapsed phases of barrerite. In L.B. Sand and J. Mumpton, Eds., Natural Zeolites. Occurrence, Properties, Use, p. 85-98. Pergamon Press, Oxford and New York.

- _ - (1983) The thermal behaviour of heulandites: structural study of the dehydration of Nadap heulandite. Tschermaks Mineralogische Petrographische Mitteilungen, 31, 259-270.

- - (1984) Topological changes in dehydrated zeolites: breaking of T-O-T oxy- gen bridges. In D. Olson and A. Bisio, Eds., Proceedings of the 6th International Zeolite Conference, Reno, p. 834-841. Butterworth, Guildford, U.K.

Alberti, A., Rinaldi, R., and Vezzalini, G. (1978) Dynamics of dehydration in stilbite-type structures; Stellerite Phase B. Physics and Chemistry of Minerals, 2, 365-375.

Alberti, A., Cariati, F., Erre, L., Piu, P., and Vezzalini, G. (1983) Spectroscopic investigation on the presence of $\mathrm{OH}$ in natural barrerite and in its collapsed phases. Physics and Chemistry of Minerals, 9, 189-191.

Alberti, A., Vezzalini, G., Cariati, F., Erre, L., and Piu, P. (1985) Dehydration and re-hydration of the zeolites with 4-4-1 SBUs: Near I.R. evidence for topological changes in heulandite I. Zeolites, 5, 289-291.

Alberti, A., Sacerdoti, M., Quartieri, S., and Vezzalini, G. (1999) Heating-induced phase transformation in zeolite brewsterite: new 4- and 5-coordinated ( $\mathrm{Si}, \mathrm{Al})$ sites. Physics and Chemistry of Minerals, 26, 181-186.

Alberti, A., Vezzalini, G., Quartieri, S., Cruciani, G., and Bordiga, S. (2001) Rehydration mechanisms in zeolites: reversibility of the TOT breaking and tetrahedral cation migration in brewsterite. Microporous and Mesoporous Materials, 42, 277-287.

Armbruster, T. (1993) Dehydration mechanism of clinoptilolite and heulandite: Single-crystal X-ray study of Na-poor, Ca-, K-, Mg-rich clinoptilolite at 100 K. American Mineralogist, 78, 260-264.

Armbruster, T. and Gunter, M.E. (1991) Stepwise dehydration of heulandite-clinoptilolite from Succor Creek, Oregon, U.S.A.: a single-crystal X-ray study at $100 \mathrm{~K}$. American Mineralogist, 76, 1872-1883.

Baerlocher, Ch., Meier, W.M., and Olson, D.H. (2001) Atlas of zeolite framework types. Elsevier, Amsterdam.

Cromer, D.T. and Waber, J.R. (1974) Atomic scattering factors for X-rays. In International Tables for X-Ray Crystallography, Vol. IV, Section 2.2, pp. 99-101. The Kynoch Press: Birmingham, U.K.

Cruciani, G., Artioli, G., Gualtieri, A., Stahl, K., and Hanson, J.C. (1997) Dehydration dynamics of stilbite using synchrotron X-ray powder diffraction. American Mineralogist, 82, 729-739.

Galli, E. and Alberti, A. (1975) The crystal structure of stellerite. Bulletin de la Société Francoise de Minéralogie et de Cristallographie, 98, 11-18.

_ _ - (1976) The crystal structure of barrerite. Bulletin de la Société Francoise de Minéralogie et de Cristallographie, 99, 331-340.

Larson, A.C. and Von Dreele, R.B. (2000) General Structure Analysis System (GSAS), Report LAUR 86-748, Los Alamos National Laboratory, Los Alamos, New Mexico.

Markgraf, S.A. and Reeder, R.J. (1985) High-temperature structure refinements of calcite and magnetite. American Mineralogist, 70, 590-60.

Meneghini, C., Artioli, G., Balerna, A., Gualtieri, A.F., Norby, P., and Mobilio, S. (2001) Multipurpose imaging-plate camera for in-situ powder XRD at the GILDA beamline. Journal of Synchrotron Radiation, 8, 1162-1166.

Merkle, A.B. and Slaughter, M. (1968) Determination and refinement of the structure of heulandite. American Mineralogist, 53, 1120-1138.

Miller, S.A. and Taylor, J.C. (1985) Neutron single crystal diffraction study of an Australian stellerite. Zeolites, 5, 7-10.

Mortier, W.J. (1983) Thermal stability of the stilbite-type framework: crystal structure of the dehydrated sodium/ammonium exchange form. American Mineralogist, 68, 414-419.

Norby, P. (1997) Synchrotron powder diffraction using imaging plates: crystal structure determination and Rietveld refinement. Journal of Applied Crystallography, 30, 21-30.

Sacerdoti, M., Vezzalini, G., and Quartieri, S. (2000) Dehydration mechanism in brewsterite: single-crystal X-ray diffraction study. Microporous and Mesoporous Materials, 41, 107-118.

Slaughter, M. (1970) Crystal structure of stilbite. American Mineralogist, 55, 387-397.

Ståhl, K. and Hanson, J.C. (1999) Multiple cation sites in dehydrated brewsterite. An in-situ X-ray synchrotron powder diffraction study. Microporous and Mesoporous Materials, 32, 147-158.

Toby, B.H. (2001) EXPGUI, a graphical user interface for GSAS. Journal of Applied Crystallography, 34, 210-213.

Werner, P.E., Eriksson, L., and Westdahl, M. (1985), TREOR, Powder Indexing Program for All Symmetries.

MANUSCRIPT RECEIVED APRIL 19, 2005

MANUSCRIPT ACCEPTED JUNE 17, 2005

MANUSCRIPT HANDLED BY PETER BURNS 